Article

\title{
Preparation and Characterization of Ultra-Lightweight Foamed Concrete Incorporating Lightweight Aggregates
}

\author{
Mohamed Abd Elrahman ${ }^{1,2}$, Mohamed E. El Madawy ${ }^{2}$, Sang-Yeop Chung ${ }^{3, *}$, Pawel Sikora ${ }^{1,4} \mathbb{D}$ \\ and Dietmar Stephan ${ }^{1}$ (I) \\ 1 Building Materials and Construction Chemistry, Technische Universität Berlin, Berlin, Gustav-Meyer-Allee \\ 25, 13355 Berlin, Germany; mohamedattia@mans.edu.eg (M.A.E.); pawel.sikora@zut.edu.pl (P.S.); \\ stephan@tu-berlin.de (D.S.) \\ 2 Structural Engineering Department, Mansoura University, Elgomhouria St., Mansoura 35516, Egypt; \\ m_eltantawy@mans.edu.eg \\ 3 Department of Civil and Environmental Engineering, Sejong University, 209 Neungdong-ro, Gwangjin-gu, \\ Seoul 05006, Korea \\ 4 Faculty of Civil Engineering and Architecture, West Pomeranian University of Technology, Szczecin, Al. \\ Piastow 50, 70-311 Szczecin, Poland \\ * Correspondence: sychung@sejong.ac.kr; Tel.: +82-2-3408-3332
}

Received: 14 February 2019; Accepted: 28 March 2019; Published: 6 April 2019

check for updates

Featured Application: This work can be useful in the development of stable ultra-lightweight foamed concrete mixtures with improved mechanical strength and decreased drying shrinkage and without deterioration in thermal insulation properties.

\begin{abstract}
Increasing interest is nowadays being paid to improving the thermal insulation of buildings in order to save energy and reduce ecological problems. Foamed concrete has unique characteristics and considerable potential as a promising material in construction applications. It is produced with a wide range of dry densities, between 600 and $1600 \mathrm{~kg} / \mathrm{m}^{3}$. However, at a low density below $500 \mathrm{~kg} / \mathrm{m}^{3}$, it tends to be unstable in its fresh state while exhibiting high drying shrinkage in its hardened state. In this study, lightweight aggregate-foamed concrete mixtures were prepared by the addition of preformed foam to a cement paste and aggregate. The focus of the research is the influence of fly ash, as well as fine lightweight aggregate addition, on the properties of foamed concrete with a density lower than $500 \mathrm{~kg} / \mathrm{m}^{3}$. Concrete properties, including stability and consistency in the fresh state as well as thermal conductivity and mechanical properties in the hardened state, were evaluated in this study. Scanning electron microscopy (SEM) was used to study the microstructure of the foamed concrete. Several mixes with the same density were prepared and tested. The experimental results showed that under the same bulk density, incorporation of fine lightweight aggregate has a significant role on compressive strength development, depending on the characteristics of the lightweight aggregate. However, thermal conductivity is primarily related to the dry density of foamed concrete and only secondarily related to the aggregate content. In addition, the use of fine lightweight aggregate significantly reduces the drying shrinkage of foamed concrete. The results achieved in this work indicate the important role of lightweight aggregate on the stability of low-density foamed concrete, in both fresh and hardened states.
\end{abstract}

Keywords: foamed concrete; density; fine lightweight aggregates; drying shrinkage 


\section{Introduction}

Foamed concrete can be considered to be a cellular material containing many pores, with their distribution, shape, and size being significant factors controlling the material characteristics of the concrete [1]. It has high flowability and high thermal insulation properties [2,3]. Foamed concrete is used as a promising construction material in several fields, due to its reduced energy consumption, low cost, high thermal insulation, and energy saving characteristics [4,5]. It has low self-weight, a low cement content, and low aggregate usage [6]. Foamed concrete can be produced with different densities, ranging from 400 to $1600 \mathrm{~kg} / \mathrm{m}^{3}$ [1,7]. Due to its numerous advantages, foamed concrete can be applied in many civil engineering areas, such as filling insulation, lightweight blocks, thermal and acoustic insulation, trench reinstatement, and soil stabilization $[6,8]$. Pore size distribution and pore volume and shape strongly affect the microstructure and characteristics of foamed concrete $[9,10]$. Chung et al. [11,12] examined the influence of pore size, distribution, and shape on the properties of foamed concrete with different densities with the help of X-ray micro-computed tomography (micro-CT) imaging. They reported that as the density increases, the size of the pores becomes smaller. Moreover, the density of the solid part of the foamed concrete influences pore size and shape because of the ability of the solid structure to hold the pores inside the concrete specimen. With increasing the foamed concrete density, the microstructure becomes more compact and denser [12]. As such, the physical and mechanical properties of foamed concrete can be adjusted by controlling its density.

Foamed concrete contains many pores, which enhances thermal insulation. However, this also has a negative effect on compressive strength and stiffness, which are both significantly decreased [13-15]. In addition to pore shape and size, foam stability has a considerable effect on the properties of foamed concrete. Several parameters influence the stability of foamed concrete, including the amount of foam added and the water content in the cement paste [16]. The basic materials for foamed concrete are cement, water, and foam. Sometimes fine sand, fly ash, superplasticizer, fibers, or silica fume are used as well [17]. Falliano et al. used directional composite grid reinforcement to improve the mechanical properties of foamed concrete [18]. For a given dry density, foamed concrete prepared using fly ash as a filler has better mechanical properties than the equivalent sand-based foamed concrete [19]. Foaming agents are commonly synthetic, with their content and type having a considerable influence on the properties of both fresh and hardened foamed concrete [20]. The quality of the foam is of great importance in the production of foamed concrete, because it influences the stability of the foamed concrete in the fresh state and significantly affects its stiffness and strength in the hardened state [21]. In foamed concrete mixtures, strength is strongly influenced by the type and dosage of foaming agent, as well as by the water:solid ratio [6]. Falliano et al. demonstrated that there is a strong relationship between the water:solid ratio and the type of foaming agent used, with both factors influencing the final characteristics of foamed concretes [22]. The stability of the concrete mix depends mainly on the water:solid ratio, as well as on the foam quantity and quality. These parameters also have considerable influence on the consistency of foamed concrete [23].

One of the main disadvantages of foamed concrete is the high drying shrinkage that takes place at early ages [24,25]. Due to the absence of coarse aggregates in the foamed concrete, its drying shrinkage is about 4-10 times higher than that of traditional concrete [6]. The incorporation of supplementary materials can reduce both drying shrinkage and hydration heat [26]. Several factors significantly affect the drying shrinkage of foamed concrete, including the water:binder ratio, foam volume, and foam agent type $[16,23]$. The addition of lightweight aggregates is considered to be an efficient method to reduce drying shrinkage [27]. Nambiar et al. [16] examined the effects of different filler materials on the shrinkage behavior of foamed concrete. They concluded that, as the filler:cement ratio increases, the shrinkage drops significantly due to the restraining influence of the increased aggregate content. Foam volume and cement paste characteristics are important factors influencing the drying shrinkage of foamed concrete [23]. The addition of fibers improves the mechanical properties of foamed concrete and reduces its drying shrinkage [28,29]. Moreover, the incorporation of mineral admixtures also affects concrete shrinkage significantly [30]. The drying shrinkage mainly depends on the type of 
fine material used; it increases with slag content and can be reduced with the use of fly ash [31,32]. Silica fume mixes suffer from cracking, which can be reduced significantly through the incorporation of polypropylene fibers.

Foamed concretes with a density lower than $600 \mathrm{~kg} / \mathrm{m}^{3}$ are being developed and applied in various applications. However, at a low density below $500 \mathrm{~kg} / \mathrm{m}^{3}$, they tend to be unstable in the fresh state and exhibit high drying shrinkage in the hardened state. Lightweight concrete with a density of $400 \mathrm{~kg} / \mathrm{m}^{3}$ has been produced through a combination of expanded polystyrene and foam [33]. Zhihua et al. [34] developed foamed concrete with a very low density $\left(<300 \mathrm{~kg} / \mathrm{m}^{3}\right)$. Huang et al. [35] reported that the addition of chemical stabilizing admixtures improves concrete stability and reduces the collapsing of foam bubbles. Foamed concrete with a density lower than $500 \mathrm{~kg} / \mathrm{m}^{3}$ has been developed, but more investigation is needed to optimize its characteristics. The target of this research is therefore to study the properties of low-density foamed concrete. As such, several foamed concretes were prepared and tested to investigate the influence of various parameters on the properties of foamed concrete, including the incorporation of fine lightweight aggregates and the addition of fly ash as a partial cement replacement material.

\section{Materials and Methods}

\subsection{Materials}

This research aimed to examine the influence of the addition of fine lightweight aggregates, as well as the partial replacement of cement with fly ash, on the characteristics of hardened foamed concrete. Several mixes with different compositions were cast and examined. Ordinary Portland cement (CEM I 52.5R), according to EN 197-1 and provided by Heidelberg Cement (Heidelberg, Germany), was used. Class F fly ash (FA) (Baumineral, Germany) was used to partially replace the cement, by $25 \mathrm{wt} \%$. Table 1 presents the physical and chemical properties of the binder used, and Figure 1 presents the particle size distributions of the binder used. Two types of fine lightweight aggregate were used. Expanded perlite, with a loose bulk density of $80 \mathrm{~kg} / \mathrm{m}^{3}$, was crushed and particles with sizes between 0.1 and $0.3 \mathrm{~mm}$ were selected. The loose bulk density of the fine perlite was $120 \mathrm{~kg} /{ }^{3}$, though its specific gravity was 2.38. In addition, fine expanded glass (Liaver with size fraction $0.1-0.3 \mathrm{~mm}$ ) had a particle density of $0.80 \mathrm{~g} / \mathrm{cm}^{3}$. The ratio of water/binder $(\mathrm{w} / \mathrm{b})$ was 0.40 for all mixtures, while the paste:foam ratio was fixed at 1:2. A foaming agent, produced by Sika Germany (Lightcrete 400), was used to produce the foam. A tailor-made polycarboxylate superplasticizer (Sika-Viscocrete) without a de-foaming agent, which was compatible with the foaming agent, was also used to ensure a workable concrete slump flow diameter higher than $500 \mathrm{~mm}$. The reason for selecting this consistency class lies in the fact that foamed concrete cannot be vibrated, due to the probability of destroying its foam bubbles. It should therefore have a high filling ability, in order to produce homogeneous samples without big voids. To enhance the stability and homogeneity of the mixture, a chemical stabilizer (a viscosity enhancing admixture, Sika ST3) was used. Six different mixes, with a density of $500 \mathrm{~kg} / \mathrm{m}^{3}$, were designed and prepared. The proportions of all the mixes are shown in Table 2.

Table 1. Chemical and physical properties of the binder used.

\begin{tabular}{ccccccccccc}
\hline Material & $\mathbf{C a O}$ & $\mathbf{S i O}_{\mathbf{2}}$ & $\mathbf{A l}_{\mathbf{2}} \mathbf{O}_{\mathbf{3}}$ & $\mathbf{F e}_{\mathbf{2}} \mathbf{O}_{\mathbf{3}}$ & $\mathbf{M g O}$ & $\mathbf{N a}_{\mathbf{2}} \mathbf{O}$ & $\mathbf{K}_{\mathbf{2}} \mathbf{O}$ & $\mathbf{S O}_{\mathbf{3}}$ & $\begin{array}{c}\text { Density } \\
\left(\mathbf{g} / \mathbf{c m}^{3}\right)\end{array}$ & $\begin{array}{c}\text { Surface Area } \\
\left(\mathbf{c m}^{2} / \mathbf{g}\right)\end{array}$ \\
\hline CEM I 52.5R & 66.2 & 20.6 & 3.3 & 4.9 & 1.3 & 0.1 & 0.43 & 2.8 & 3.15 & 3860 \\
Fly ash & 4.8 & 47.9 & 21.0 & 4.6 & 1.4 & 0.7 & 1.1 & 0.8 & 2.27 & 2930 \\
\hline
\end{tabular}




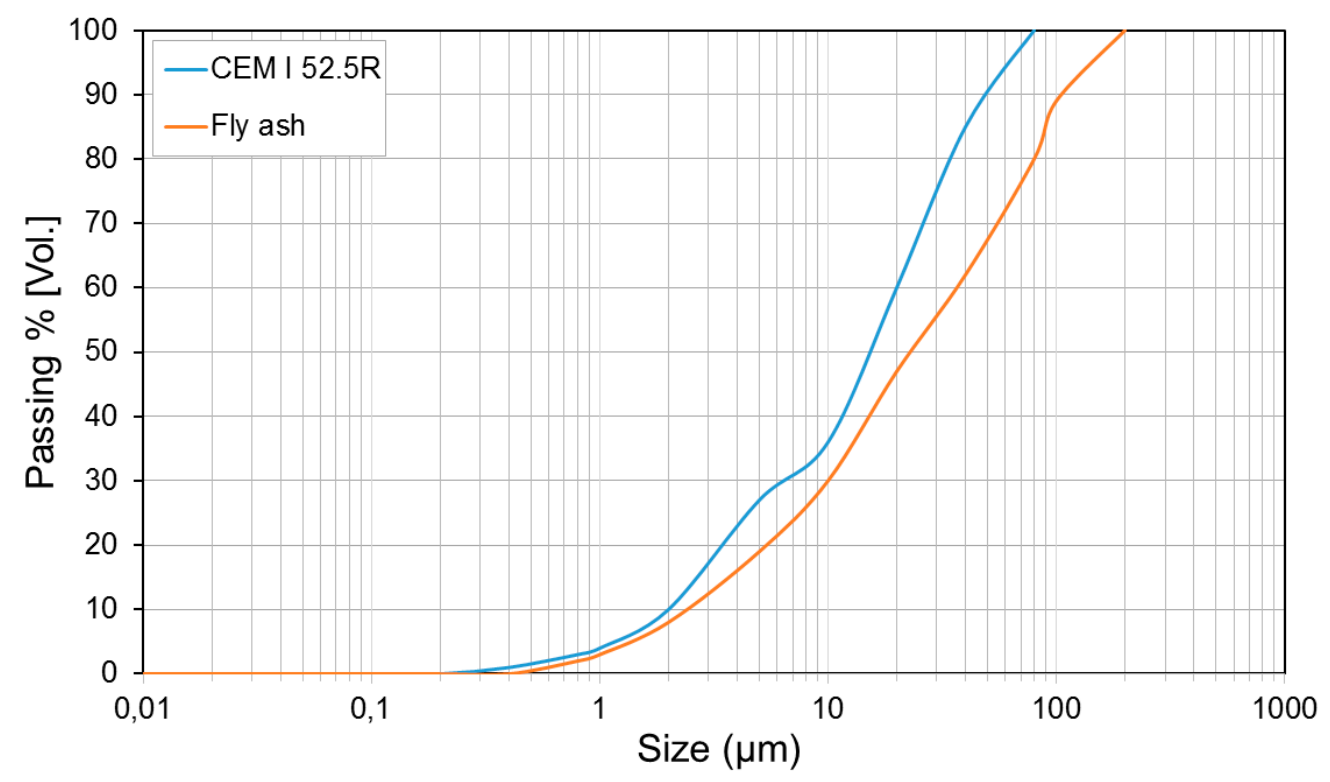

Figure 1. Particle size distributions of the fine materials used.

Table 2. Mix compositions of foamed concrete.

\begin{tabular}{cccccccc}
\hline Mix & Designation & $\begin{array}{c}\text { Cement (C) } \\
\left(\mathbf{k g} / \mathbf{m}^{\mathbf{3}}\right)\end{array}$ & $\begin{array}{c}\text { Fly Ash (FA) } \\
\left(\mathbf{k g} / \mathbf{m}^{\mathbf{3}}\right)\end{array}$ & $\begin{array}{c}\text { Fine Perlite } \\
\mathbf{( F P )}(\mathbf{L})\end{array}$ & $\begin{array}{c}\text { Fine Liaver } \\
(\mathbf{F L}) \mathbf{( L )}\end{array}$ & $\begin{array}{c}\text { Paste:Foam } \\
\text { Fresh Density } \\
\left(\mathbf{k g} / \mathbf{m}^{\mathbf{3}}\right)\end{array}$ \\
\hline 1 & C & 400 & - & - & - & $1: 2$ & 596 \\
2 & C/FA & 300 & 100 & - & - & $1: 2$ & 610 \\
3 & C/FA/FP50 & 300 & 100 & 50 & - & $1: 2$ & 595 \\
4 & C/FA/FP100 & 300 & 100 & 100 & - & $1: 2$ & 584 \\
5 & C/FA/FL50 & 300 & 100 & - & 50 & $1: 2$ & 565 \\
6 & C/FA/FL100 & 300 & 100 & - & 100 & $1: 2$ & 580 \\
\hline
\end{tabular}

\subsection{Foamed Concrete Preparation}

A foam generator-SG S9 provided by Sika Germany-was used to produce the foam. The dosage of the foaming agent was $2 \mathrm{wt} \%$ of the water, with an applied water pressure of $3 \mathrm{bar}$. As recommended by the provider, the foam should be continuously produced without pulses in order to achieve a high foam stability. Accordingly, compressed air pressure should be adopted until foam is produced uniformly and steadily. The foam density was measured at about $35 \mathrm{~kg} / \mathrm{m}^{3}$. In the mixing process, cement, water, fly ash, and fine lightweight aggregates were mixed in an Eirich mixer with a high shear intensity, to homogeneously distribute the cement and fine materials and to prevent the agglomeration of the particles. Concurrently, foam was produced with the required volume being measured out. Fifty liters of Zyklos concrete mixer was used to mix the foam and the paste. One portion of the paste per volume was mixed with two portions of the foam produced per volume. The fresh properties, including a flow table test according to EN 206-1, were measured, but without dropping or raising (jolting) the flow table, as this may affect the stability of the foam bubbles. Thereafter, $100 \mathrm{~mm}$ cubic molds were filled without compaction. After two days, the concrete specimens were demolded and cured in a climate chamber with controlled humidity and temperature of $99 \%$ and $21^{\circ} \mathrm{C}$, respectively. A compressive strength test, using $100 \mathrm{~mm}$ cubes, was carried out according to EN 12390-3 at 28 days. Three cubes of each type of concrete were tested, with the mean value considered in this evaluation. The drying shrinkage of the foamed concrete was measured as specified in DIN 52450, using the Graf-Kaufmann method, in which prisms with sample sizes of $40 \times 40 \times 160 \mathrm{~mm}^{3}$ are tested at appropriate time intervals. For thermal conductivity measurements, a Hot Disk device, according to ISO 22007-2, was used. Measurement was carried out by positioning a sensor between two samples; in this case the sensor was concurrently used as both a temperature monitor and a current supplier [11]. 


\section{Results and Discussion}

\subsection{Foamed Concrete Density}

In this investigation, foamed concrete mixes were calculated as having a dry density ranging from 450 to $500 \mathrm{~kg} / \mathrm{m}^{3}$. The mixes were designed based on the concept that chemically bound water is about $20 \mathrm{wt} \%$ of cement content. The slump flow of all mixes was measured and adopted by adjusting the superplasticizer dosages to achieve the targeted consistency class of F3/F4 (EN 206-1). The mixes developed had high stability without segregation or bleeding. Figure 2 shows the hardened densities of the foamed concrete. It is clear from the results that the concrete density obtained was close to the designed values $\left(450-500 \mathrm{~kg} / \mathrm{m}^{3}\right)$. Small variations in the dry densities of the foamed concrete mixes can be observed due to the incorporation of fine lightweight aggregates and fly ash. The incorporation of fly ash slightly increased the dry density of the foamed concrete. This improves the microstructure of the foamed concrete, because of its high filling ability [36]. However, the addition of fine Liaver reduced the dry density of the foamed concrete significantly, because of its low specific gravity. Compared to the fine Liaver mixes, the foamed concrete mixes incorporated with fine perlite exhibited higher dry density, because of the high specific gravity of the crushed perlite.

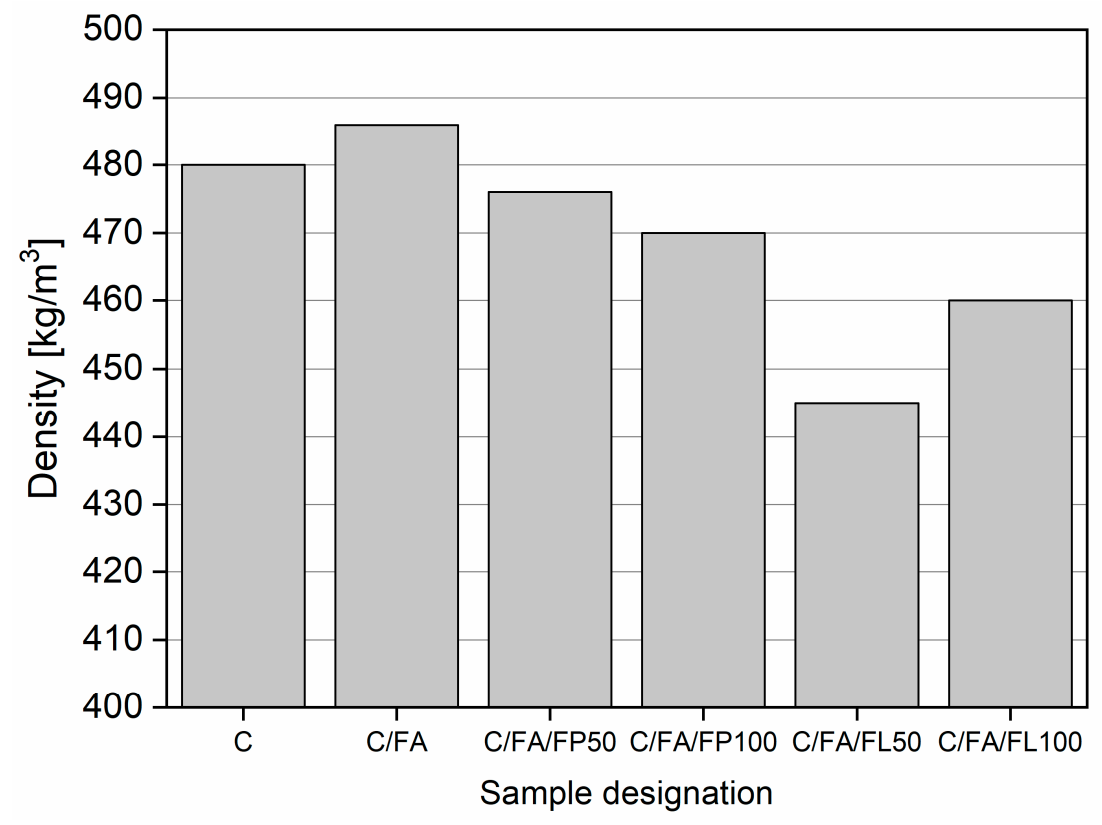

Figure 2. Dry densities of foamed concrete mixes.

\subsection{Compressive Strength}

Figure 3 presents the experimental results of the compressive strength tests of the foamed concrete mixes. All the mixes had a compressive strength higher than $1 \mathrm{MPa}$, reaching $3.8 \mathrm{MPa}$ for mix C/FA/FP50, which is superior to the strength of foamed concrete with the same density class found in the literature [6]. It is obvious from the results that the compressive strength of foamed concrete depends mainly on both mixture composition and dry density. Compared to the control mix with cement $(\operatorname{mix} \mathrm{C})$, the addition of fly ash (mix C/FA) increased the dry density and reduced the compressive strength. For mixes with the same binder content (mixes C/FA/FP50 and C/FA/FP100), the compressive strength increased with dry density. When the density was reduced, the compressive strength decreased significantly (mixes C/FA/FL50 and C/FA/FL100). Incorporation of fly ash as a cement replacement by $25 \mathrm{wt} \%$ had a marginal influence on the dry density, from 480 to $486 \mathrm{~kg} / \mathrm{m}^{3}$, as a result of the difference in specific gravity between cement and fly ash. However, significant effects were clearly detected in the results of compressive strength tests. Here, there was a reduction from the 3.35 $\mathrm{MPa}$ of the control mix (mix C) to $1.25 \mathrm{MPa}$ for the mix with fly ash (mix C/FA). This strength 
degradation can be explained by the slow hydration rate of fly ash as compared to cement, which affects concrete strength negatively. By adding fly ash to the foamed concrete, the dry density increased by about $2 \%$, while the compressive strength fell by about $62 \%$.

The use of fine lightweight aggregates affected the mechanical properties of the foamed concrete, as can be seen from the results of the compressive strength tests in Figure 3. No clear trend could be observed regarding the influence of fine lightweight aggregates on foamed concrete strength. The addition of fine perlite (with a specific density of $2.38 \mathrm{~g} / \mathrm{cm}^{3}$ ) increased the compressive strength (mixes C/FA/FP50 and C/FA/FP100), as compared to the mix with fly ash (mix C/FA). This can be attributed to the high fineness and pozzolanic activity of fine perlite, as has been reported by other researchers [37]. On the other hand, fine Liaver did not affect the compressive strength of foamed concrete clearly. The density of foamed concrete with fine Liaver was lower than that of the control mix. A small improvement in compressive strength was detected in foamed concrete mixes with fine Liaver. Fine Liaver is a non-reactive material which is lighter than fly ash. As a result, in comparison to the fly ash mix (mix C/FA), the fine Liaver mix had a lower density and a marginally higher strength. Compared to the control mix, foamed concrete mixes with Liaver (C/FA/FL50 and C/FA/FL100) exhibited lower compressive strength. This can be attributed to the low cement content in the Liaver mixes, because of the addition of aggregate to the paste. In addition, the incorporation of fly ash in the Liaver mixes reduced their compressive strength as a result of Liaver's low hydration rate, as compared to cement.

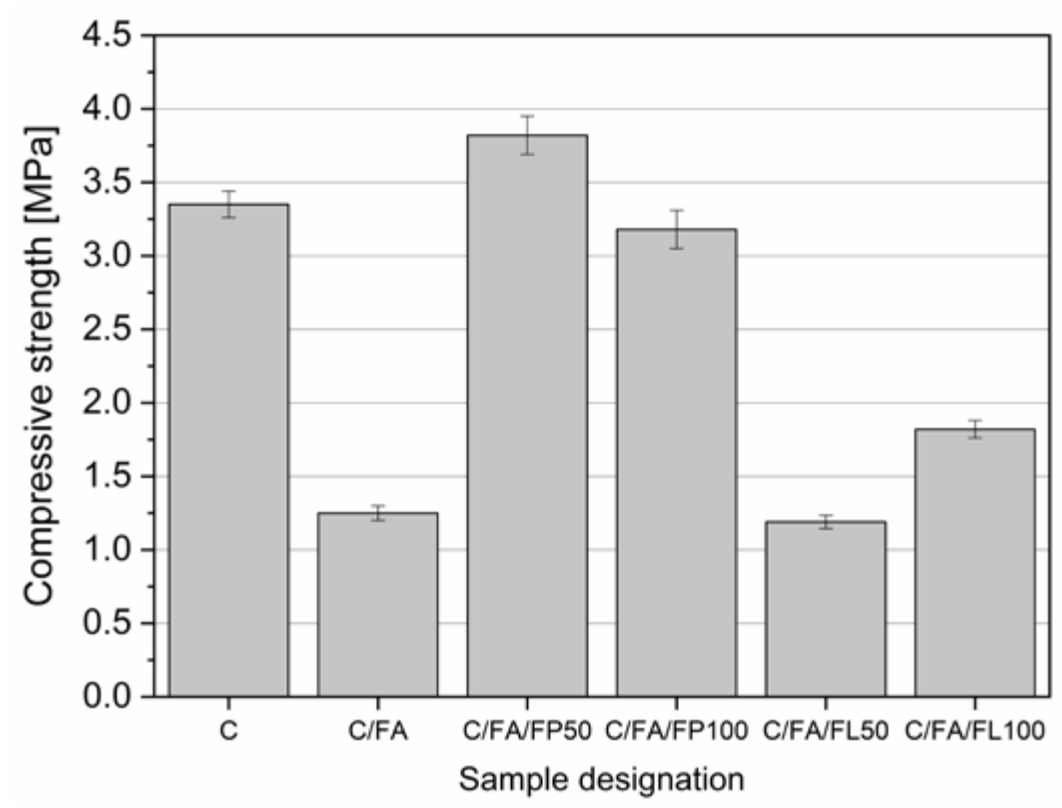

Figure 3. Compressive strength of foamed concrete mixes at 28 days.

\subsection{Thermal Conductivity}

Because of the cellular microstructure of foamed concrete, its insulation properties are very important. In this investigation, the thermal conductivity of foamed concrete was measured using a Hot Disk. Because of the high sensitivity of thermal conductivity tests to the moisture content of the concrete, the concrete samples were oven-dried at $105{ }^{\circ} \mathrm{C}$ until a constant mass was reached. The thermal conductivity measurements were carried out after cooling to room temperature at zero humidity conditions. Cubical samples with $100 \mathrm{~mm}$ edge sizes were used, with the measurements performed on all sides. Two samples were needed for each measurement, with the Hot Disk sensor being fixed between samples. The mean value of the six values obtained by the Hot Disk was calculated and used in this investigation. Figure 4 shows the experimental results of the thermal conductivity tests of foamed concrete. It is immediately obvious that the thermal properties of foamed 
concrete were mainly dependent on density. The control mix (mix $\mathrm{C}$ ) had a thermal conductivity of about $0.136 \mathrm{~W} /(\mathrm{m} \cdot \mathrm{K})$, which increased to about $0.14 \mathrm{~W} /(\mathrm{m} \cdot \mathrm{K})$ for mix C/FA (with fly ash) due to the increase in dry density. Conversely, mix C/FA/FL50 had the lowest thermal conductivity of about $0.113 \mathrm{~W} /(\mathrm{m} . \mathrm{K})$; this can also be attributed to its decreased dry density, as compared to the other mixes. The composition of the mix or the filler type did not have a significant influence on thermal conductivity. Thermal conductivity increased with density and vice versa. These experimental results do not indicate a clear influence of fine aggregate addition on the thermal conductivity of foamed concrete. The incorporation of fine lightweight aggregate reduced the dry density, and as a consequence the thermal conductivity of the foamed concrete fell. Other researchers have also found a correlation between thermal conductivity and pore size distribution [38,39]. The connectivity of the pores, in addition to their size, can affect the thermal conductivity of concrete significantly. However, in this research this influence was not clear, perhaps due to the very high porosity of the ultra-lightweight concrete produced.

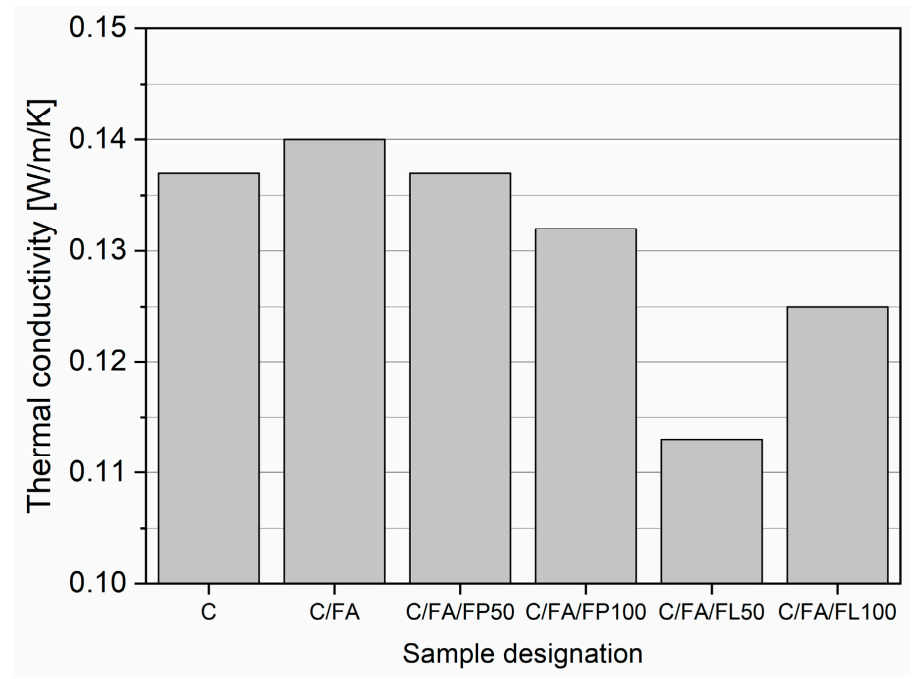

Figure 4. Thermal conductivity of foamed concrete mixes.

\subsection{Drying Shrinkage}

In general, drying shrinkage is considered to be one of the main disadvantages of foamed concrete, because of the absence of coarse aggregates. Figure 5 presents the experimental results of drying shrinkage tests of the foamed concrete, using the Graf-Kaufmann method at an age of 28 days. It is clear that the addition of fly ash reduced drying shrinkage by about $30 \%$. The incorporation of fine perlite increased shrinkage, with this being attributable to the characteristics of perlite; that is, its high water absorption which influences shrinkage. Conversely, the addition of fine Liaver reduced drying shrinkage significantly to about one third (Mix 6) of the drying shrinkage of the control mix. From these results, it can be concluded that drying shrinkage is reliant on mixture composition, as well as on the density of the foamed concrete. Lightweight aggregates can reduce shrinkage, depending on their type and characteristics. Expanded glass (Liaver) exhibited smaller drying shrinkage, since the Liaver grains have a higher restraining capacity for shrinkage as compared to cement particles. A combination of expanded glass (Liaver) and fly ash significantly reduced the drying shrinkage of foamed concrete. Fine Liaver is a non-reactive material, and it therefore does not undergo much volumetric change, meaning that it can restrain the development of cracking and shrinkage. The water absorption of fine perlite is much higher than that of fine Liaver, which can result in significant drying shrinkage. 


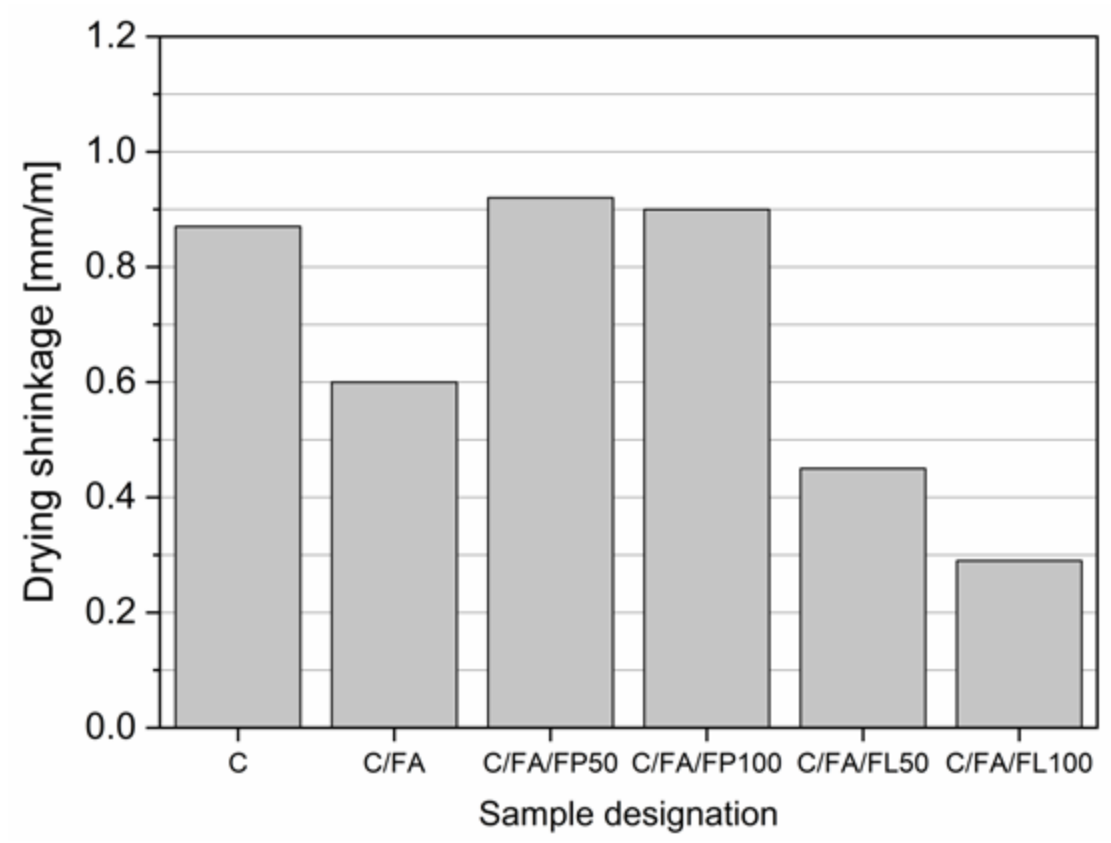

Figure 5. Drying shrinkage of foamed concrete mixes at 28 days.

\subsection{Foamed Concrete Microstructure}

Scanning electron microscopy (SEM) was used to examine the microstructural characteristics of the foamed concrete. Figure 6 shows the light microscopic images of the control mix (mix C) as well as those of the fly ash mix (mix C/FA), and Figure 7 shows the SEM images. Foam bubbles can be easily detected in the images, and a wall between the bubbles can also be observed. Most of the pores had diameters in the range of 50-500 $\mu \mathrm{m}$. In addition, the products of cement hydration grew in the voids. In the second mix (mix C/FA), non-reacted fly ash spheres appeared, which explains the low compressive strength of the fly ash foamed concrete. Similar to the control mix, the hydration products of the cement grew in the voids. The images show the homogenous distribution of foam and the cement matrix, without the agglomeration of cement particles or the collapse of foam bubbles. However, at a sample age beyond 28 days, non-reacted fly ash particles can be easily seen in the images. In addition, the thickness of the walls between foam bubbles became thicker due to the addition of fly ash. These observations explain the role of fly ash in increasing the density and reducing the strength of foamed concrete. The SEM images also indicate that, because of the high amount of foam in the mix, the bubbles were very close to each other, thus explaining the low compressive strength of ultra-lightweight foam concrete.
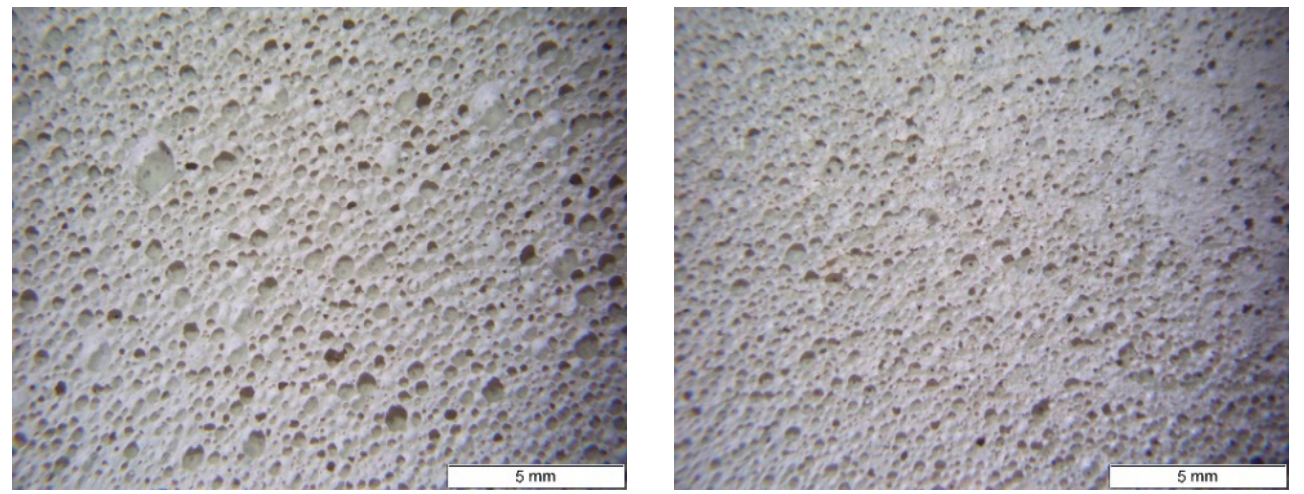

Figure 6. Light microscopic images of foamed concrete: control mix, C (left), C/FA (right). 


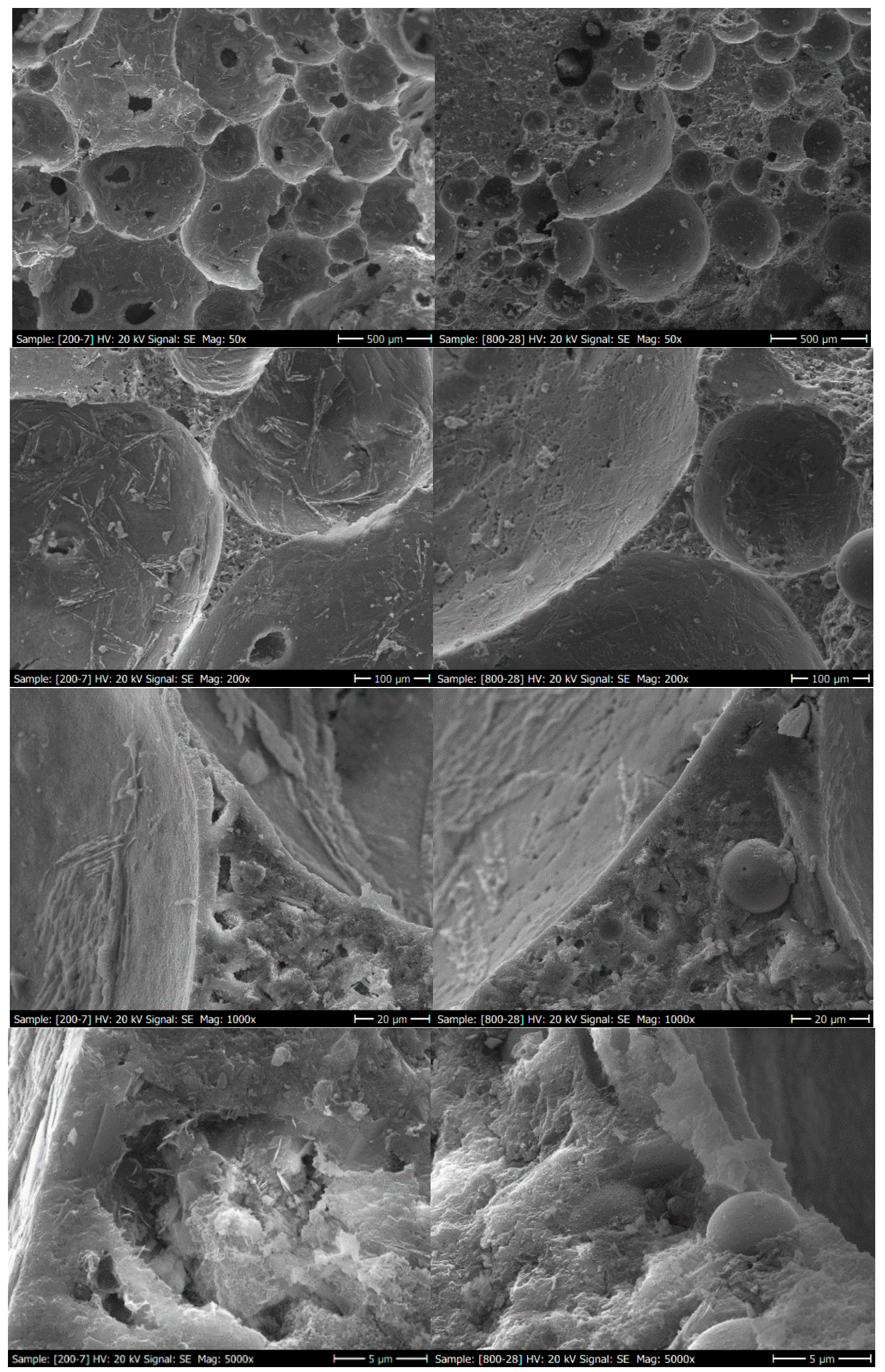

Figure 7. Scanning electron microscopy (SEM) images of foamed concrete mixes: control mix, C (left) and fly ash mix, C/FA (right). 


\section{Conclusions}

In this study, the effects of using fly ash and fine lightweight aggregates on the properties of foamed concrete with a density lower than $500 \mathrm{~kg} / \mathrm{m}^{3}$ were investigated. Based on the experimental results, the following conclusions can be drawn:

1. The incorporation of fly ash slightly increases the dry density of foamed concrete, while fine lightweight aggregates have a varied influence because of their different characteristics.

2. Dry density, as well as mixture composition, influences the compressive strength of foamed concrete. As the dry density increases, so too does the compressive strength.

3. Fine perlite is more effective in improving the compressive strength of foamed concrete than fine Liaver.

4. The thermal conductivity of foamed concrete depends mainly on concrete density, with the mix composition having a minimal influence.

5. Fly ash reduces the drying shrinkage of foamed concrete.

6. Fine Liaver significantly reduces the shrinkage of foamed concrete to about $30 \%$, with fine perlite increasing the drying shrinkage only marginally.

7. Because of the slow hydration rate of fly ash, it has a negative influence on the compressive strength of foamed concrete.

Author Contributions: Conceptualization, M.A.E., M.E.E.M., and S.-Y.C.; methodology, M.A.E. and S.-Y.C.; validation, M.A.E., S.-Y.C., and M.E.E.M.; investigation, M.A.E., M.E.E.M., and P.S.; resources, D.S.; writing-original draft preparation, M.A.E and M.E.E.M.; writing-review and editing, M.A.E, S.-Y.C., and D.S.; visualization, M.A.E. and P.S.; supervision, D.S.; funding acquisition, D.S. and M.E.E.M.

Funding: The project is supported by the German Federal Ministry of Education and Research (BMBF, Project number: 13XP5010B and 01DR16007) and by the Polish National Academy for Academic Exchange within project No. PPN/BEK/2018/1/00078.

Acknowledgments: The authors would like to express our appreciation to Heidelberg Cement and Sika companies for providing materials and devices. We would like also to thank Christian Lehmann from TU Berlin for supporting this research with SEM measurements.

Conflicts of Interest: The authors declare no conflict of interest.

\section{References}

1. Lim, S.K.; Tan, C.S.; Lim, O.Y.; Lee, Y.L. Fresh and hardened properties of lightweight foamed concrete with palm oil fuel ash as filler. Constr. Build. Mater. 2013, 46, 39-47. [CrossRef]

2. Lim, S.K.; Tan, C.S.; Li, B.; Ling, T.; Hossain, M.U.; Poon, C.S. Utilizing high volumes of quarry wastes in the production of lightweight foamed concrete. Constr. Build. Mater. 2017, 151, 441-448. [CrossRef]

3. Yang, K.H.; Lee, K.; Song, J.; Gong, M. Properties and sustainability of alkali-activated slag foamed concrete. J. Clean. Prod. 2014, 68, 226-233. [CrossRef]

4. Kearsley, E.P.; Wainwright, P.J. The effect of porosity on the strength of foamed concrete. Cem. Concr. Res. 2002, 32, 233-239. [CrossRef]

5. Wei, S.; Yiqiang, C.; Yunsheng, Z.; Jones, M.R. Characterization and simulation of microstructure and thermal properties of foamed concrete. Constr. Build. Mater. 2013, 47, 1278-1291. [CrossRef]

6. Mugahed Amran, Y.H.; Farzadnia, N.; Abang Ali, A.A. Properties and applications of foamed concrete; a review. Constr. Build. Mater. 2015, 101, 990-1005. [CrossRef]

7. Zhao, X.; Lim, S.K.; Tan, C.S.; Li, B.; Ling, T.; Huang, R.; Wang, Q. Properties of foamed mortar prepared with granulated blast furnace slag. Materials 2015, 8, 462-473. [CrossRef]

8. Othuman, M.A.; Wang, Y.C. Elevated-temperature thermal properties of lightweight foamed concrete. Constr. Build. Mater. 2011, 25, 705-716. [CrossRef]

9. Yang, K.-H.; Lo, C.-W.; Huang, J.-S. Production and properties of foamed reservoir sludge inorganic polymer. Constr. Build. Mater. 2014, 50, 421-431. [CrossRef]

10. Hilal, A.A.; Thom, N.H.; Dawson, A.R. On void structure and strength of foamed concrete made without/with additives. Constr. Build. Mater. 2015, 85, 157-164. [CrossRef] 
11. Chung, S.-Y.; Lehmann, C.; Abd Elrahman, M.; Stephan, D. Pore characteristics and their effects on the material properties of foamed concrete evaluated using micro-CT images and numerical approaches. Appl. Sci. 2017, 7, 550. [CrossRef]

12. Chung, S.-Y.; Lehmann, C.; Abd Elrahman, M.; Stephan, D. Microstructural characterization of foamed concrete with different densities using microscopic techniques. Cem. Wapno Beton 2018, 3, 216-225.

13. Jones, M.; McCarthy, A. Heat of hydration in foamed concrete: Effect of mix constituents and plastic density. Cem. Concr. Res. 2006, 36, 1032-1041. [CrossRef]

14. Sayadi, A.; Tapia, J.; Neirzert, T.; Clifton, G. Effect of expanded polystyrene (EPS) particles on fire resistance, thermal conductivity and compressive strength of foamed concrete. Constr. Build. Mater. 2016, 112, 716-724. [CrossRef]

15. Hilal, A.; Thom, N.; Dawson, A. On entrained pore size distribution of foamed concrete. Constr. Build. Mater. 2015, 75, 227-233. [CrossRef]

16. Nambiar, E.; Ramamurthy, K. Shrinkage behavior of foamed concrete. J. Mater. Civ. Eng. 2009, 21, 631-636. [CrossRef]

17. Gökçe, H.S.; Hatungimana, D.; Ramyar, K. Effect of fly ash and silica fume on hardened properties of foam concrete. Constr. Build. Mater. 2019, 194,1-11. [CrossRef]

18. Falliano, D.; De Domenico, D.; Ricciardi, G.; Gugliandolo, E. Improving the flexural capacity of extrudable foamed concrete with glass-fiber bi-directional grid reinforcement: An experimental study. Compos. Struct. 2019, 209, 45-59. [CrossRef]

19. Jones, M.; McCarthy, A. Utilising unprocessed low-lime coal fly ash in foamed concrete. Fuel 2005, 84, 1398-1409. [CrossRef]

20. Falliano, D.; Domenico, D.; Ricciardi, G.; Gugliandolo, E. Experimental investigation on the compressive strength of foamed concrete: Effect of curing conditions, cement type, foaming agent and dry density. Constr. Build. Mater. 2018, 165, 735-749. [CrossRef]

21. Panesar, D.K. Cellular concrete properties and the effect of synthetic and protein foaming agents. Constr. Build. Mater. 2013, 44, 575-584. [CrossRef]

22. Falliano, D.; De Domenico, D.; Ricciardi, G.; Gugliandolo, E. Key factors affecting the compressive strength of foamed concrete. IOP Conf. Ser. Mater. Sci. Eng. 2018, 431, 6. [CrossRef]

23. Ramamurthy, K.; Kunhanandan Nambiar, E.K.; Indu Ranjani, G. A classification of studies on properties of foam concrete. Cem. Concr. Compos. 2009, 31, 388-396. [CrossRef]

24. Sun, C.; Zhu, Y.; Guo, J.; Zhang, Y.; Sun, G. Effects of foaming agent type on the workability, drying shrinkage, frost resistance and pore distribution of foamed concrete. Constr. Build. Mater. 2018, 186, 833-839. [CrossRef]

25. Wan, K.T.; Zhu, H.; Yuen, T.; Chen, B.; Hu, C.; Leung, C.; Kuang, J. Development of low drying shrinkage foamed concrete and hygro-mechanical finite element model for fabricated building fascade applications. Constr. Build. Mater. 2018, 165, 939-957. [CrossRef]

26. Chindaprasirt, P.; Rukzon, S.; Sirivivatnanon, V. Resistance to chloride penetration of blended Portland cement mortar containing palm oil fuel ash, rice husk ash and fly ash. Constr. Build. Mater. 2008, 22, 932-938. [CrossRef]

27. Weigler, H.; Karl, S. Structural lightweight aggregate concrete with reduced density lightweight aggregate foamed concrete. Int. J. Cem. Compos. Lightweight Concr. 1980, 2, 101-104. [CrossRef]

28. Falliano, D.; De Domenico, D.; Ricciardi, G.; Gugliandolo, E. Compressive and flexural strength of fiber-reinforced foamed concrete: Effect of fiber content, curing conditions and dry density. Constr. Build. Mater. 2019, 198, 479-493. [CrossRef]

29. Bing, C.; Zhen, W.; Ning, L. Experimental research on properties of high-strength foamed concrete. J. Mater. Civ. Eng. 2011, 24, 113-118. [CrossRef]

30. Mermerdas, K.; Arbili, M. Explicit formulation of drying and autogenous shrinkage of concretes with binary and ternary blends of silica fume and fly ash. Constr. Build. Mater. 2015, 94, 371-379. [CrossRef]

31. Hu, X.; Shi, Z.; Shi, C.; Wu, Z.; Tong, B.; Ou, Z.; Schutter, G. Drying shrinkage and cracking resistance of concrete made with ternary cementitious components. Constr. Build. Mater. 2017, 149, 406-415. [CrossRef]

32. Shariq, M.; Prasad, J.; Abbas, H. Creep and drying shrinkage of concrete containing GGBFS. Cem. Concr. Compos. 2016, 68, 35-45. [CrossRef]

33. Chen, B.; Liu, N. A novel lightweight concrete-fabrication and its thermal and mechanical properties. Constr. Build. Mater. 2013, 44, 691-698. [CrossRef] 
34. Zhihua, P.; Hengzhi, L.; Weiqing, L. Preparation and characterization of super low density foamed concrete from Portland cement and admixtures. Constr. Build. Mater. 2014, 72, 256-261.

35. Huang, Z.; Zhang, T.; Wen, Z. Proportioning and characterization of Portland cement-based ultra-lightweight foam concretes. Constr. Build. Mater. 2015, 79, 390-396. [CrossRef]

36. Roderick, J.; Kezban, O.; Li, Z. High-volume, ultra-low-density fly ash foamed concrete. Mag. Concr. Res. 2017, 69, 1146-1156.

37. Tajra, F.; Abd Elrahman, M.; Chung, S.; Stephan, D. Performance assessment of core-shell structured lightweight aggregate produced by cold bonding pelletization process. Constr. Build. Mater. 2018, 179, 220-231. [CrossRef]

38. Sang, G.; Zhu, Y.; Yang, G.; Zhang, H. Preparation and characterization of high porosity cement-based foam material. Constr. Build. Mater. 2015, 91, 133-137. [CrossRef]

39. Falliano, D.; Gugliandolo, E.; de Domenico, D.; Ricciardi, G. Experimental Investigation on the Mechanical Strength and Thermal Conductivity of Extrudable Foamed Concrete and Preliminary Views on Its Potential Application in 3D Printed-RILEM International Conference on Concrete and Digital Fabrication; Springer: Berlin, Germany, 2018; Volumes 277-286.

(C) 2019 by the authors. Licensee MDPI, Basel, Switzerland. This article is an open access article distributed under the terms and conditions of the Creative Commons Attribution (CC BY) license (http:/ / creativecommons.org/licenses/by/4.0/). 